\title{
Laughing seizures due to a midline intraventricular neoplasm in tuberous sclerosis
}

\author{
Saman Gunatilake, D G Harendra De Silva
}

\begin{abstract}
Laughing seizures have been described in association with hypothalamic hamartomas and precocious puberty. Laughing seizures due to a neoplasm arising from the floor of the left lateral ventricle extending down towards the hypothalamus in a child with tuberous sclerosis is reported. This combination has not been reported before and emphasises the importance of imaging to diagnose such midline lesions in children with paroxysmal laughing.

(Arch Dis Child 1995; 72: 443-444)
\end{abstract}

Keywords: tuberous sclerosis, gelastic seizures, hypothalamic neoplasms.

Laughing seizures may be idiopathic or may be associated with intracranial mass lesions in the region of the hypothalamus, limbic system, or the temporal lobe. These seizures are also known as gelastic seizures and consist of stereotyped attacks of laughter varying from grinning, giggling, to joyful weeping. Laughing seizures due to hypothalamic neoplasms have been reported before. We report a case of laughing seizures in a child with tuberous sclerosis due to a neoplasm arising from the floor of the left lateral ventricle extending down towards the hypothalamic region. This combination has not been reported before. Paediatrics, University of Ruhuna, Galle, Sri Lanka

D G H De Silva

Correspondence to:

Dr Saman Gunatilake, 43

Fife Road, Colombo-5, Sr Lanka.

Accepted 23 January 1995

\section{Case report}

This boy first developed seizures at the age of 8 months. These seizures consisted of tonic, clonic movements of either upper limb
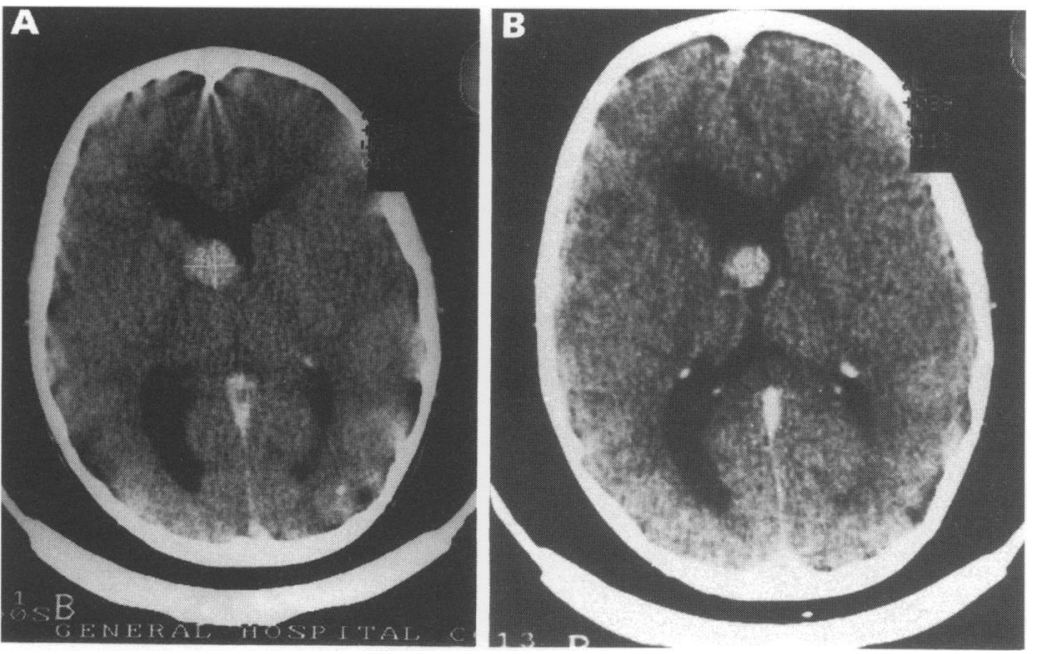

Figure 1 (A) Rounded enhancing neoplasm arising close to the left foramen of Monro. (B) Subependymal calcified glial nodules. lasting for about a minute and the child was unconscious. These seizures occurred at the rate of one to two a week and the response to treatment was poor. Neurologically the child did not have any abnormality at that time and his motor and mental development were normal. Though he continued to have seizures, the child developed normally and at the age of 5 years he started having episodes of inappropriate laughter. These occurred almost daily, mostly in the mornings. He had warning of the impending seizure and clung to his mother and then started laughing. $\mathrm{He}$ also had involuntary movements of the right arm during the seizure.

$\mathrm{He}$ is now 7 years old and attends a normal school. Physical and mental development was normal and his intelligence is comparable with other normal children of his age. He is an only child from a non-consanguineous marriage. The parents do not have any features of tuberous sclerosis. There were three white skin macules measuring about 1 to 2 inches on his trunk and limbs. He had no facial angiofibromas. There were no other skin lesions, and he had no papilloedema or retinal lesions. Electroencephalography showed paroxysmal high amplitude polyspike and wave complexes in all areas. Computed tomography showed a rounded, well circumscribed enhancing neoplasm arising from the floor of the left lateral ventricle close to the foramen of Monro and extending downwards into the hypothalamic region (fig 1A) and subependymal calcified glial nodules (fig 1B). Ventricular dilation was noted on the left side, a result of the tumour causing obstruction to the foramen of Monro. Magnetic resonance imaging in addition to showing the neoplasm revealed the presence of multiple cortical and subcortical tubers (fig 2A, B).

\section{Discussion}

The association of gelastic seizures with hypothalamic neoplasms is now well recognised and is considered a specific epileptic syndrome. ${ }^{1}$ Precocious puberty is an associated feature in most cases and may follow gelastic seizures. $^{2}$ This association has led to the suggestion that a centre for laughter exists in the region of the hypothalamus. Differentiating gelastic seizures from psychiatric disease or behavioural abnormalities may be difficult. Our patient illustrates some of the differentiating features that favour the diagnosis of seizures. The seizure episodes were sudden in onset, brief, stereotyped, and occurred in a child without any history of psychiatric or behavioural problem. Often the laughter in a gelastic seizure is of a different 

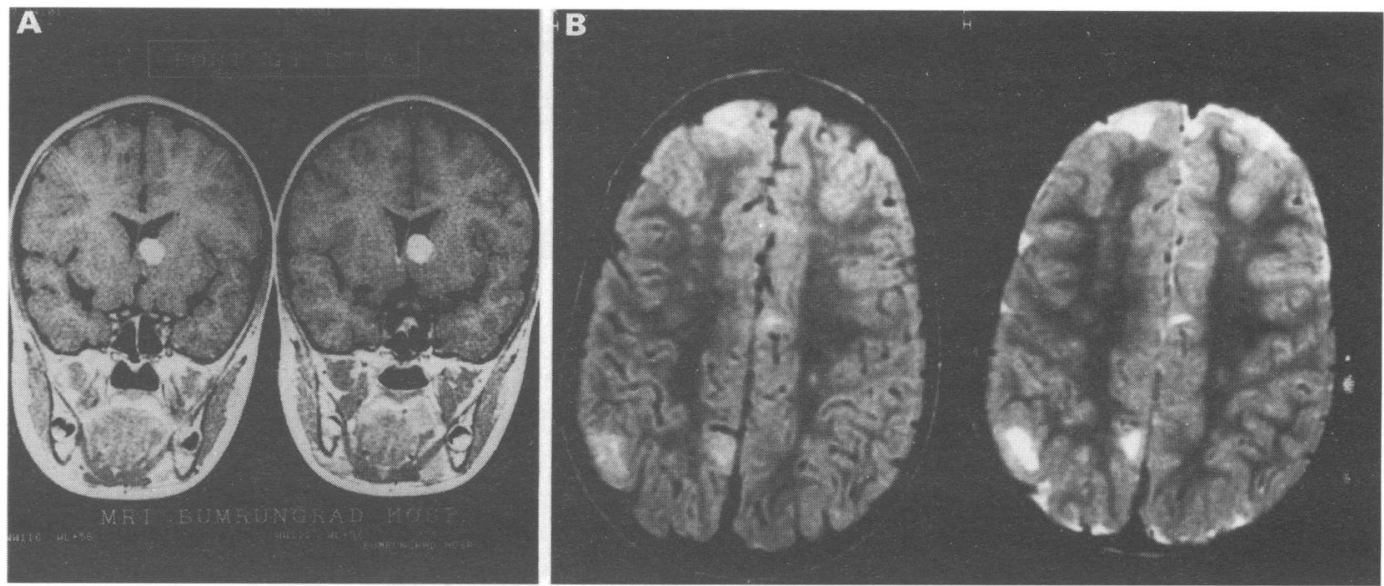

Figure 2 (A) Gadolinium enhanced neoplasm extending down towards the hypothalamus. (B) Multiple cortical tubers.

quality to laughter seen naturally. Because of the association with intracranial mass lesions, it is necessary to exclude this possibility by careful evaluation using proper imaging methods. More cases are now recognised because of advanced imaging methods. Giant cell astrocytomas occur in about $10 \%$ of patients with tuberous sclerosis and almost all are located in the region of the foramen of Monro. ${ }^{3}$ In our patient, though we have no histological proof, the imaging features are suggestive of a giant cell astrocytoma. The occurrence of laughing seizures in this child led us to suspect a lesion situated close to the midline. It is surprising that gelastic seizures due to lesions in the region of the hypothalamus have not been described before in tuberous sclerosis.

1 Berkovic SF, Andermann F, Melanson D, Ethier RE, Feindel W, Gloor P. Hypothalamic hamartomas and ictal laughter evolution of a characteristic epileptic syndrome and diagnostic value of magnetic resonance imaging. Ann Neurol 1988; 23: 429-39.

2 Penfold JL, Manson JI, Caldicott WM. Laughing seizures and precocious puberty. Australian Paediatric fournal 1978, 14: $185-90$.

3 Huttenlocher PR. Tuberous sclerosis. In: Matthews WB Glaser GH, eds. Recent advances in clinical neurology - 4 . New York: Churchill Livingstone, 1984: 281-98. 